\title{
Grain Size Analysis of Class C Fly ash Used for Aluminium-Silicate Binders Production
}

\author{
Tomasz Z. Błaszczyński ${ }^{1}$ and Maciej R. Król ${ }^{2}$ \\ ${ }^{1}$ 62-002 Złotniki, Poland, tomasz.blaszczynski@opal.info.pl \\ ${ }^{2}$ Koszalin University of Technology, Śniadeckich 2, 75-453 Koszalin, krol@wilsig.tu.koszalin.pl
}

\begin{abstract}
Concrete structures are constantly moving in the direction of improving the durability. Durability depends on many factors, which are the composition of concrete mix, the usage of additives and admixtures and also the place, where material will work and carry the load. Taking into account that the consumption of cement on the globe gives way only to the consumption of drinking water, the issue of concrete technology begins to take on an economic and ecological aspect. Mentioned above the aspect of durability is strictly connected to economy. Due to huge amount of greenhouse gasses produced in the process of calcination, the ordinary Portland cements are responsible for even $8 \%$ of anthropogenic carbon dioxide production. This paper is focused on properties of materials known as green binders. They can be used to produce aluminium-siliceous binders and green concretes which can also be known as geopolymer concretes. Often used in construction industry, class F fly ashes are also good substratum also for aluminium- siliceous binders. Nevertheless amount of available class $F$ fly ashes do not give the possibility to replace ordinary cements by aluminium-silicate one produced from this type of ash. This raises the need to look for replacement solutions for the substrate of the new green adhesive. As the substrate of new eco-binders there were used fly ash which came from coal and high calcium ash from the burning of lignite, called class $C$ fly ashes. However not processed one, cannot compete with Portland cements due to durability. It surely depends on many aspects of polymerization process, which are for example maturation environment, concentration and type of alkaline activator, but the most important are parameters of fly ash substrate. This is because main attention was paid to granulation of examined class $C$ fly ashes which have been subjected to a grinding process involving milling in a magnetic mill and subjected to ultrasonic waves. The analysis of grain change was presented in the aspect of the possibility of increasing the strength and durability of the cement material.
\end{abstract}

Keywords: Aluminium-Silcate Cements, Green Cements, Type C Fly Ash.

\section{Introduction}

In recent years, many different kinds of cementiious materials have been developed. Many of them were alkali-activated cementiious materials. It is mostly because of their high strength and durability. Moreover they have got very low environmental impact due to emissions of greenhouse gasses which was subject in some papers (Błaszczyński et al. 2014, 2015; Juenger et al. 2011 and Barbosa et al. 2000). Most of used in civil-engineering and infrastructural construction fly ashes are type F. The reason of that is because of their excellent properties and wide spectrum of application. Much worse properties, especially in use as additives to cements and mortars gives usage of type C fly ash. According to Yang (Yang et al. 2008), 
aluminosilicate materials obtained from alkali-activated class $\mathrm{F}$ fly ash have main binding phase as the amorphous hydrated alkali-aluminosilicate (Krizana et al. 2002; Haha et al. 2011 and Guo et al. 2010) proved that the major binding phase in alkali-activated ground granulated blast furnace slag similarly like in type $\mathrm{C}$ fly ash is calcium silicate hydrate $(\mathrm{C}-\mathrm{S}$ $\mathrm{H})$. Because of this fact, main goal of this paper is to present future possibilities of treatment which could increase application range and utilization of $\mathrm{C}$ type fly ash.

Alkali-activated slag cements show good mechanical strength. Their strength, compressive and flexural can be even better than in ordinary cements which were shown by Hardjito and others (Hardjito et al. 2005; Wallah et al. 2006 and Cheng et al. 2003). The classical cements set owing to the special phenomenon of solvation, i.e. hydration. It is a compound process due to overlapping and a mutual influence of individual clinker phases that react with water. The total hydration process consists of three basic stages. The dissolution of soluble compounds in water, that is the proper hydration, which consists in the creation of the primary phase in a colloidal state (the formation of the plastic mass) and the crystallization of the hydration products (hardening of the plastic mass) what was presented by Błaszczyński and Król (Błaszczyński et al. 2015). The initial stage of the proper hydration of cement was presented by Kurdowski (Kurdowski, 2010). It is connected first of all with the $\mathrm{C}_{3} \mathrm{~A}$ phase. As a result of a fast reaction of this phase, large crystals of hydrated calcium aluminates are produced (Figure 1a). All the stages of hydration, as compared with the setting of the polymeric blend, are presented in Figure. 1.
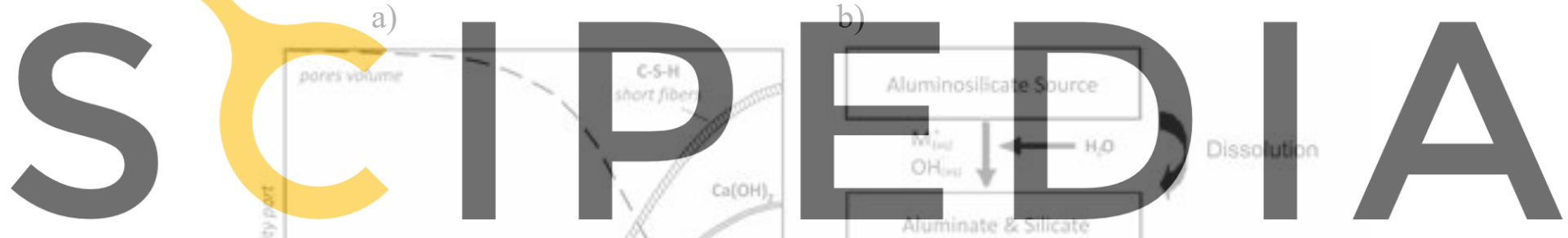

Register for free at https//www.scipedia.com to downtoad the version without the watermark
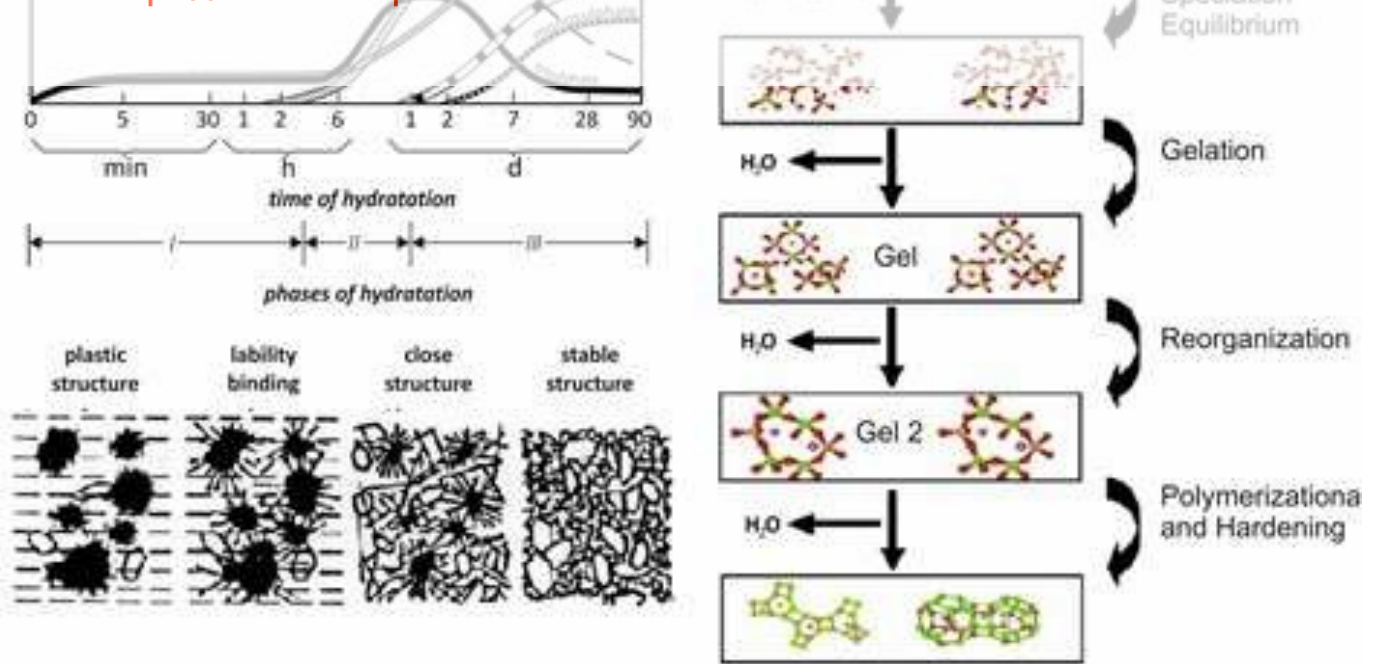

Figure 1. Comparison of phases: a) hydration of the Portland cement, b) polymerization. 
The present state of knowledge was collated by Skvara (Skvara, 2007). It gives the possibility to present that a geopolymer based on fly ash is characterized by following properties:

- is built by structure similar to vitreous bodies what was presented by Barbosa and Mackenzie (Barbosa et al., 2000),

- in structure of geopolymers there is presence of sodium and potassium cations $\left(\mathrm{Na}^{+}\right.$, $\mathrm{K}^{+}$), which are not bonded so strong as it is in zeolite, it is a reason of potential efflorescence occurrence,

- structure of material is represented by a porous body,

- porous body of geopolymers contain water,

- the water is used in geopolymerization process as a transport of alkali activator,

- amorphous hydrates and crystalline can be noticed in structure only if material containing calcium are present (i.e. blast furnace slag, calcium fly ash).

A number of characteristics and properties of materials that are by-products in various processing processes are strictly conditioned by the technological cycle. Whether in the case of fly ash or blast furnace slag, temperature plays a major role in the quality of the products obtained, in addition to the properties and composition of the substrate. The higher it is, the cleaner the product is, the more finely divided it is, and the more extensive it can be used. What's more, the implication of binders in open atmosphere conditions is also possible, without the need for high-temperature ripening conditions. This situation occurs in the case of both fly ash and blast furnace slag what was topic of Małolepszy and Deja (Małolepszy et al, 1999). The substrate used in the reactions in which the above by-products are formed
determines the use of temperatures appropriate for the given reaction and technology.
Małolepszy and Deja (Małolepszy et al., 1999) suggest in their work, where the photos taken
by scanning microscopes of fly ash samples firom power plants and combined heat and power
plants, in which varidus technologies of coal combustion differing among other temperatures of this process were used, that there is possible to systematize the composition of the sample

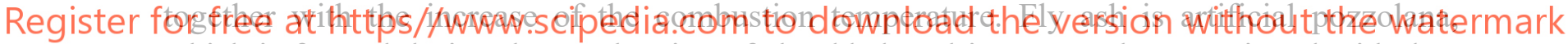
which is formed during the combustion of shredded coal in power plants equipped with dust boilers. Pozzolans do not self-harden after mixing with water. However, when they are finely ground after the addition of water, they react with calcium hydroxide, forming a mixture of aluminium silicates and calcium silicates with increasing strength and that has been proven by Barbosa and others (Barbosa et al., 2000; Duxson et al., 2007 and Caijum et al,. 2011). The pozzolanic activity of ashes is significantly affected by their particle size. As the grain increases, the pozzolanic activity decreases. Fractions smaller than $45[\mu \mathrm{m}]$ can characterize pozzolanic activity significant for building materials

\section{Experimental Program}

\subsection{Materials}

Fly ash from brown coal combustion with a significant content of calcium compounds was used for the research. In the determined samples, the $\mathrm{CaO}$ content ranged from 15 to $24 \%$. The samples were not cleaned of unburned coal, which was present in the composition in the size of approx. 3 to $5 \%$. The chemical composition of tested fly ash is given bellow (Table 1). 
As the activator, an aqueous solution of potassium hydroxide with a given molar ratio was used (Table 2). Aggregate was not added to the mix.

Table 1. Summary of the chemical composition used for testing fly ash.

\begin{tabular}{cccccccccc}
\hline $\begin{array}{c}\text { Type of fly } \\
\text { ash }\end{array}$ & $\mathrm{SiO}_{2}$ & $\mathrm{Al}_{2} \mathrm{O}_{3}$ & $\mathrm{Fe}_{2} \mathrm{O}_{3}$ & $\mathrm{TiO}_{2}$ & $\mathrm{MgO}$ & $\mathbf{C a O}$ & $\mathrm{Na}_{2} \mathrm{O}$ & $\mathrm{K}_{2} \mathrm{O}$ & $\begin{array}{c}\text { Ignition } \\
\text { losses }\end{array}$ \\
\hline TYPE C & 44,17 & 21,79 & 4,58 & 1,85 & 1,49 & 21,06 & 0,23 & 0,19 & 4,64 \\
\hline
\end{tabular}

Table 2. Properties of used alkaline activator.

\begin{tabular}{cccc}
\hline Name & $\begin{array}{c}\text { Molar mass } \\
{[\mathbf{g} / \mathbf{m o l}]}\end{array}$ & $\begin{array}{c}\text { Density } \\
{\left[\mathbf{g} / \mathbf{c m}^{\mathbf{3}}\right]}\end{array}$ & Viscosity cP \\
\hline potassium hydroxide & $56,11^{*}$ & 2,12 & - \\
\hline
\end{tabular}

\subsection{Mixes Design and Specimens Preparation}

For the first $12 \mathrm{~h}$, the samples were kept at $80^{\circ} \mathrm{C}$, and then were reaching their final proporties in air-dry conditions. After 24 hours of implementation, they were demoulded and successively tested for strength. The selection of such temperature and treatment time was the result of previous tests. $80^{\circ} \mathrm{C}$, the tested binder of calcium fly ash had ideal ripening condition surroundings. As the alkaline aetivator, the strongest arailable bases of potassium hy droxide were used in the concentration of $12 \mathrm{M}$. The influence of activator concentration on the tested

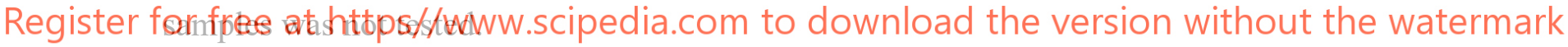

\subsection{Methods}

The treatment impact study was carried out on calcium fly ash. They have been checked for grain size. The material was then milled in an electromagnetic mill distinguishing samples in terms of milling time. After milling, the samples were examined for granulation and subjected to ultrasonic waves. After this treatment, the grain size of the material was again tested. This was to break down any agglomerates formed during grinding. Due to the limited amount of substrate that can be tested and the large number of millings, the test was carried out for times of $15,30,60,120,180$ and $240 \mathrm{~s}$, respectively.

Research related to determining the basic mechanical properties of geopolymer binders from treated ash in the form of milling was carried out on 40x40x40 mm cubic samples.

This allowed achieving additional volumes using less ash used. Two series of tests were obtained in this way:

- I - testing the efficiency of grinding substrates in the form of calcareous fly ashes by checking the difference in compressive strength of the ground substrate,

- $\quad$ II - testing the efficiency of grinding substrates in the form of calcareous fly ashes by checking the difference in tensile strength when splitting the ground substrate (Figure 2-3). 

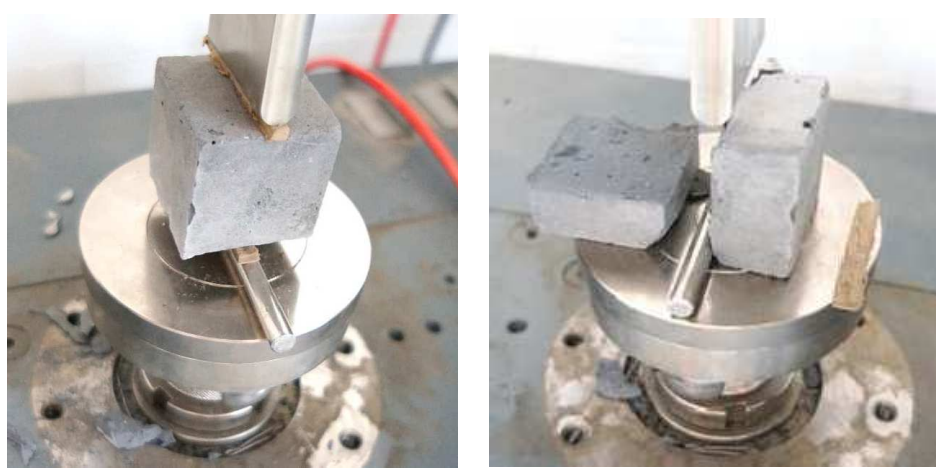

Figure 2-3. View of the sample before and after the splitting test

\section{Results and Discussion}

First obtained result was the effect of grinding and ultrasound treatment on grain size of tested samples. Grain size after grinding in times of 15, 30, 60, 120, 180 and 240 s, compared to samples additional subjected to ultrasound treatment is shown below (Figure 4-10).

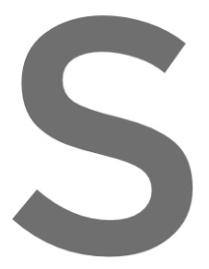

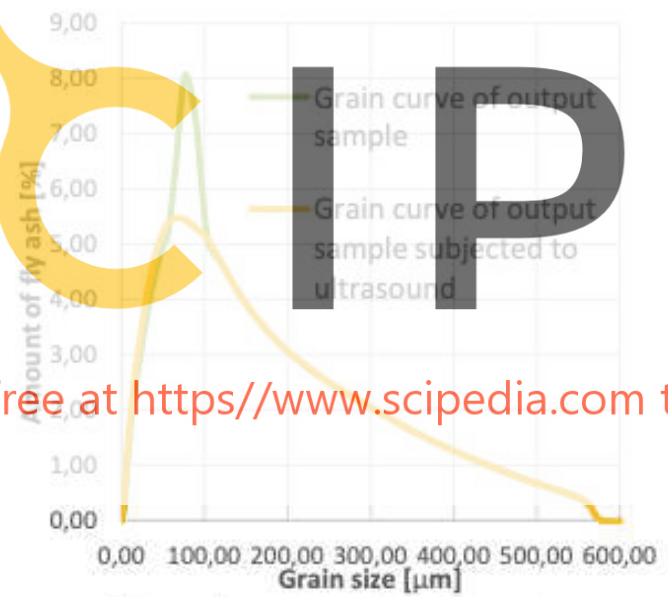

Figure 4. Grain size of output sample.

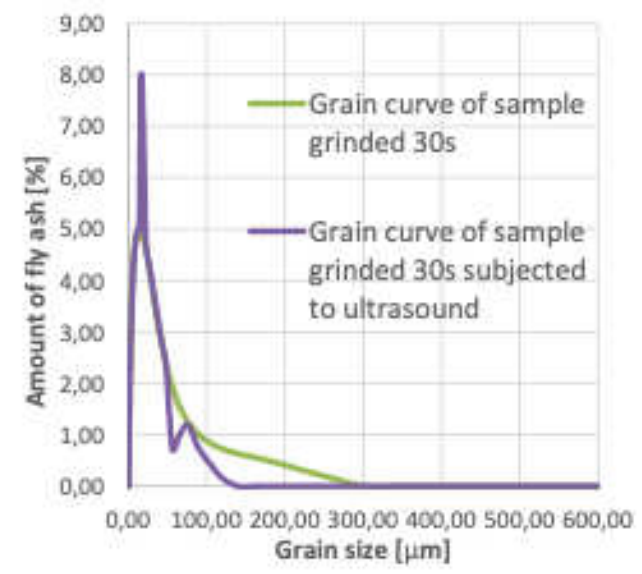

Figure 6. Grain size of sample grinded for 30s.

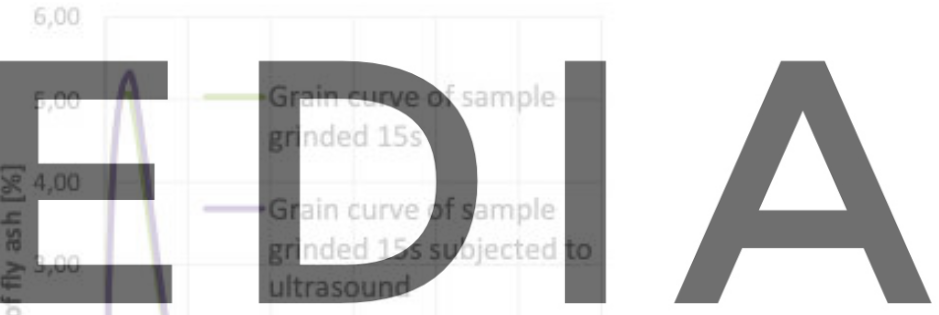

落, 00

Register for frèe at https//www.scipedia.com to download the version without the watermark

0,00

$$
\begin{gathered}
0,00100,00200,00300,00400,00500,00600,00 \\
\text { Grain size [ } \mu \mathrm{m}]
\end{gathered}
$$

Figure 5. Grain size of sample grinded for $15 \mathrm{~s}$.

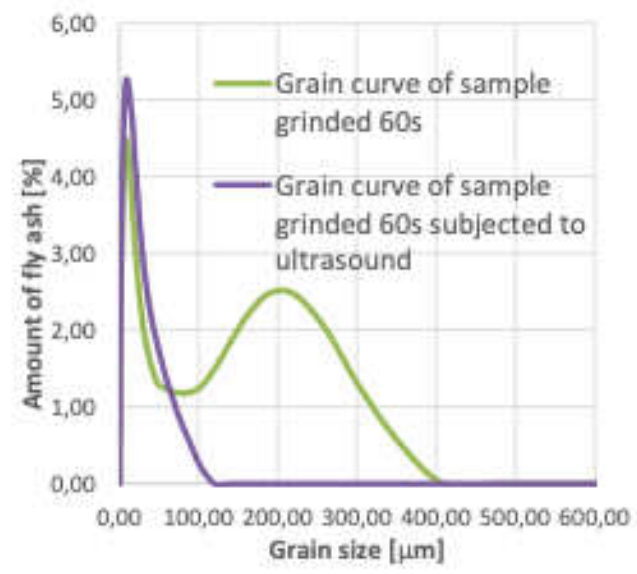

Figure 7. Grain size of sample grinded for $60 \mathrm{~s}$. 


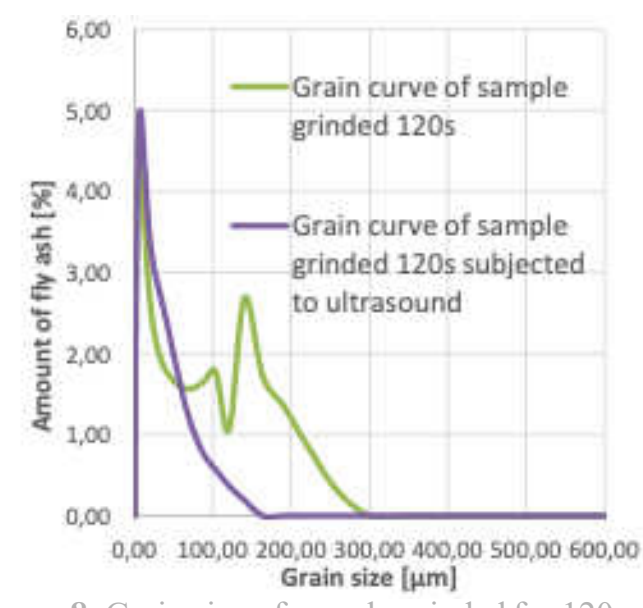

Figure 8. Grain size of sample grinded for 120s,

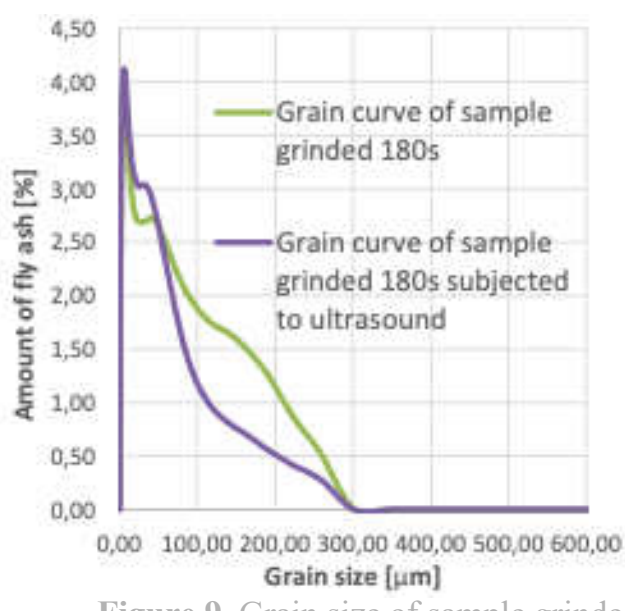

Figure 9. Grain size of sample grinded for 180s.

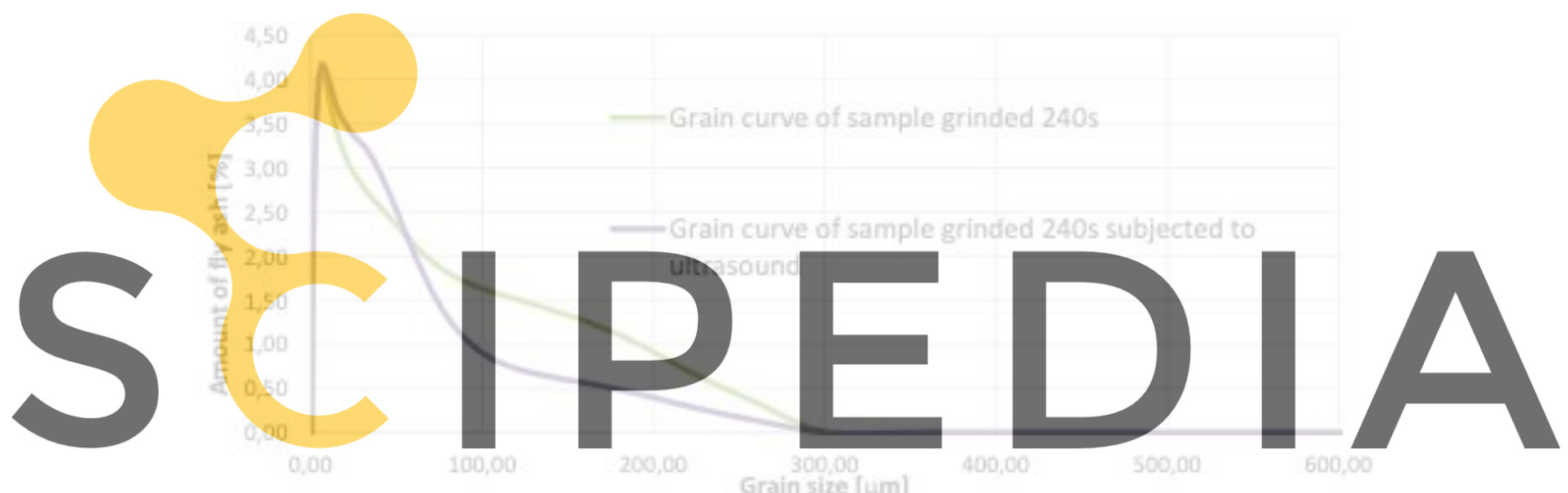

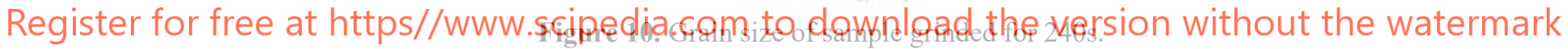

The most favourable in terms of maximum fragmentation turned out to be grinding time of 60s. During it, the highest ash content below $45 \mu \mathrm{m}$ was obtained. Further increase in grinding time caused the opposite effect agglomerates began to form in the material. This happened because smaller particles of ash under the influence of fragmentation obtained greater pozzolanic reactivity, due to which under the influence of a small amount of moisture and heat generated during grinding they merged into larger particles. The next stage of treatment was subjecting the material to an ultrasonic wave, which broke the agglomerates formed, making the sample with the largest fragmentation become a milled sample for 120 [s]. The degree of comminution described by the specific surface in this case corresponded to the obtained compressive strength of the tested samples. The increase in tensile strength for the reference sample, which was a mixture constituting $50 \%$ of the ground material for $120 \mathrm{~s}$ and $25 \%$ of the value of the ground material for 30 and 240 [s], respectively, should be considered significant. The material obtained after mixing these components was characterized by the relatively largest amount of the finest material, with a grain size less than $10[\mu \mathrm{m}]$ in relation to the amount of material less than $45[\mu \mathrm{m}]$, and the most even distribution of grain size in the range of 10-45 [ $\mu \mathrm{m}]$ (Figure 11-12). 


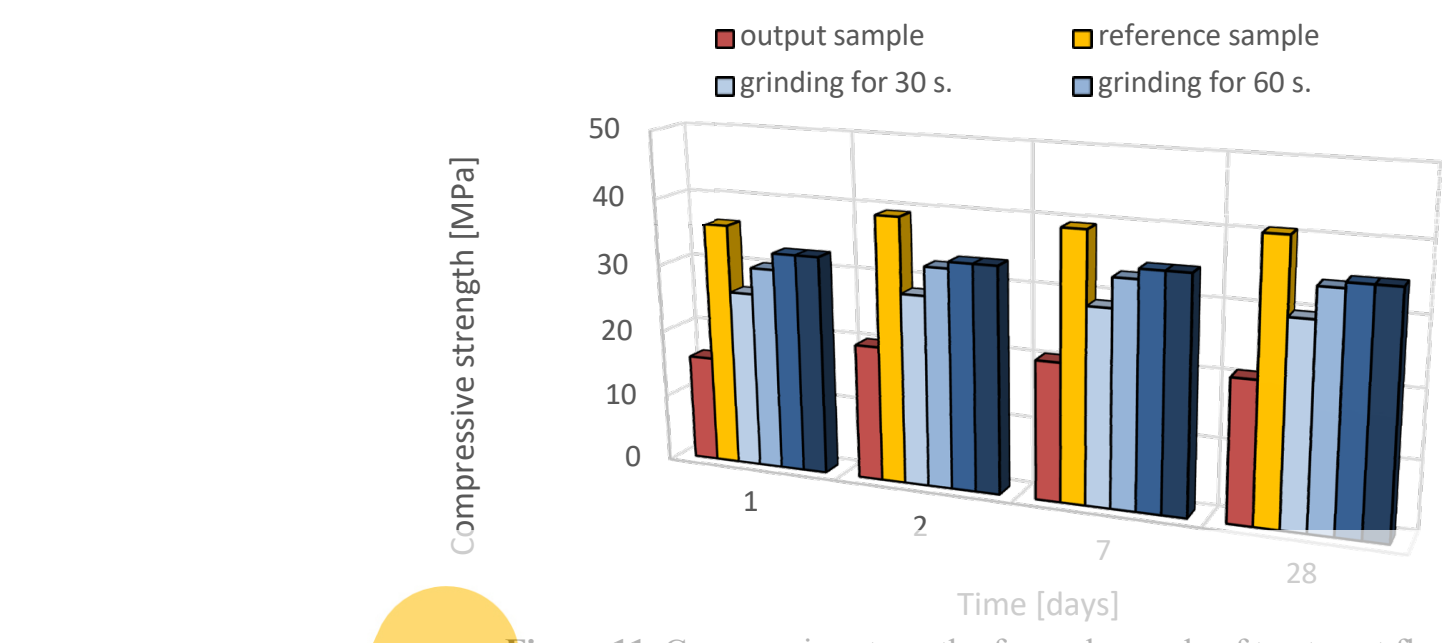

Figure 11. Compressive strength of samples made of treatment fly ash.
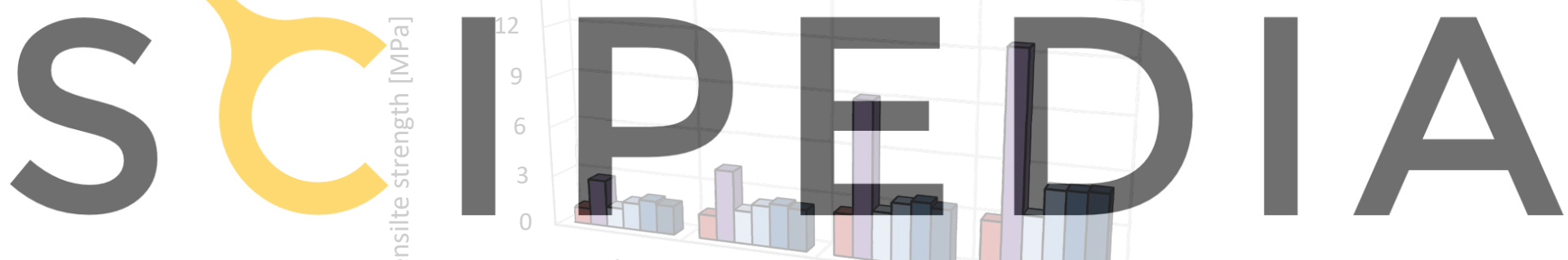

Register for free at https//www.scipedia.com

Figure 12. Tensile strength of samples made of treatment fly ash.

\section{Conclusions}

The strength results of binders made on the basis of calcium fly ash subjected to treatment in the form of ash milling show three basic relationships. First of all, milling of ashes has a significant impact on the achieved compressive and tensile strength of the tested samples. The most effective in terms of strength parameters of samples obtained from the tested ashes is the milling time of $120 \mathrm{~s}$. Its increase did not cause a significant increase in compressive strength and in the case of tensile strength even a decrease in strength. The use of a mix of ashes with different grinding times had a positive effect on the increase of compressive and tensile strength as well as the ratio of these strengths. This was probably caused by a change in the form of granulometric distribution, which has a major impact on the rate and degree of geopolymerization. 


\section{ORCID}

Tomasz Z. Błaszczyński: https://orcid.org/0000-0003-3177-9654

Maciej R. Król https:// orcid.org/0000-0002-8459-2837

\section{References}

Barbosa, V.F.F. and Mackenzie, K.J.D. (2000). Synthesis and characterization of materials based on inorganic polymers of alumina and silica: sodium polysialate polymers. Int. J. Inorg. Mater, 2(4), 309-317.

Błaszczyński, T. and Król, M. (2014). Durability of Green-Concretes, Proceedings of $8^{\text {th }}$ International Conference AMCM 2014, Wrocław, Poland, 530-540.

Błaszczyński, T. and Król, M. (2015). Usage of green concrete technology in civil engineering. Procedia Engineering, 122, $296-301$.

Błaszczyński, T. and Król, M. (2015). Durability of cement and geopolymer composites, 18th International Conference on Composite Structures ICCS18, Lisbona, 15-18.06.2015.

Błaszczyński, T. and Król, M. (2015). Geopolimers in construction. Civil and Environmental Engineering Reports, 16(1), 25-40

Caijum, S., Fernandez-Jimenez, A.M. and Palomo A. (2011). New cements for the $21^{\text {st }}$ century: The pursuit of an alternative to Portland cement. Cement and Concrete Research, 750-763.

Cheng, T. W. and Chiu J.P. (2003). Fire-resistant Geopolymer Produced by Granulated Blast Furnace Slag. Minerals Engineering, 3, 205-210.

Duxson, P., Fernandez-Jimenez, A.M., Provis, J.L., Lukey, G.C., Palomo, A. and van Deventer, J.S.J. (2007). Geopolymer technology: the current state of the art, Advances in geopolymer science \& technology, J Mater Sci 2007, 2917-2933

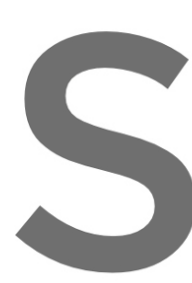

Guo, X., Shi, H, and Dick, ash geopolymer. Cement

Haha, M.B., Saout, G.L., W kinetics, hydrate assern and Concrete Research,

Hardjito, D. and Rangan, Concrete, Research Repo
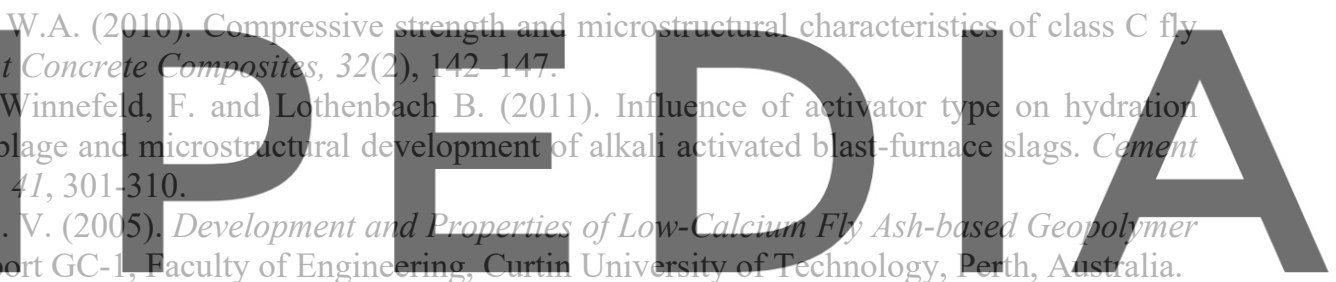

Juenger, M.C.G., Winnefeld, F., Provis, J.L. and Ideker J. (2011). Advances in alternative cementitious binders.

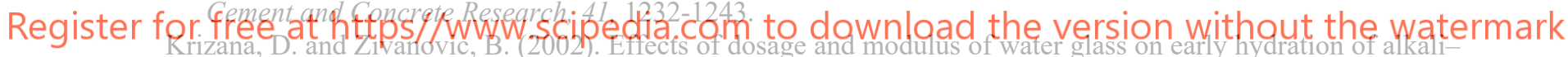
slag cements. Cement and Concrete Research, 32, 1181-1188.

Kurdowski, W. (2010). Chemistry of cement and concrete, Polish Cement Sp. z o.o., PWN (in Polish).

Małolepszy, J. and Deja J. (1999). Durability of alkali activated slag mortars and concretes, 2nd International Conference of Alkaline Cements and Concretes, Kiev, 685-697.

Yang, X., Ni, W., Zhang, X. and Wang, Y. (2008). Effect of alkali-activation on aluminosilicate-based cementitious materials. Journal of Beijing University of Science and Technology, 15(6),796-801.

Skvara F. (2007). Alkali activated materials of geopolymers?, Ceramics - Silikaty 51 (3), 173-177.

Wallah S.E., Rangan, B.V. (2006). Low-Calcium Fly Ash-Based Geopolymer Concrete: Long-Term Properties, Research Report GC2, Faculty of Engineering. Curtin University of Technology, Perth, Australia. 